\title{
Of Temples and Plane Trees: the Hippocratic Legacy as Collective Memory
}

\author{
Gerasimos P. Sykiotis ${ }^{1}$, George D. Kalliolias ${ }^{2}$, Christos Terezis ${ }^{2}$, \\ Athanasios G. Papavassiliou ${ }^{3}$
}

\author{
${ }^{1}$ Department of Biomedical Genetics, University of Rochester Medical Center, Rochester NY, USA, \\ ${ }^{2}$ Department of Philosophy, School of Humanities \& Social Sciences, University of Patras, Patras, Greece, \\ ${ }^{3}$ Department of Biochemistry, School of Medicine, University of Patras, Patras, Greece
}

In the homeland of Hippocrates, the study of the history and philosophy of medicine is remarkably infrequent among medical practitioners. It is excluded from the curricula of the majority of medical schools and from the hobbies and pastimes of most physicians and medical students. Nevertheless, medicine cannot be completely understood - and, therefore, cannot be ideally practiced - without a basic appreciation of its history, and of its underlying philosophy. In this vein, it has been gratifying that a young journal like Hormones has featured in its Historical Notes section a series of articles celebrating Hippocrates, the unambiguously accepted "father of medicine". Professor Marketos and colleagues have discussed the nascency of endocrine terminology in the Corpus Hippocraticum (the collection of writings attributed to Hippocrates), ${ }^{1}$ and they have traced the origins of the concept of homeostasis and of the term gene in Hippocrates's humoral theory and views on heredity, respectively., ${ }^{2,3}$ More recently, Professor Daikos elegantly outlined the "Hippocratic spirit" by summarizing the methodological and

Address correspondence and requests for reprints to: Gerasimos P. Sykiotis, M.D., Ph.D., Research Associate, Department of Biomedical Genetics, University of Rochester Medical Center, 14642 Rochester, NY USA, Tel.: (+1)585-273-1968; Fax: (+1)585-273-1420, e-mail: gerasimos_sykiotis@urmc.rochester.edu Received 15-09-04, Revised 20-11-04, Accepted 05-12-04 humanitarian principles that Hippocrates introduced to medicine. ${ }^{4}$ In the present Note, we will attempt to interpret why reference to Hippocrates and his contribution to medicine is not a phenomenon particular to Greek physicians. Conversely, invoking Hippocrates is a recurring pattern among physicians, historians, and philosophers of all cultures and all times, ${ }^{5}$ and we would like to propose a plausible explanation for this enduring popularity.

Consider, for example, the following striking coincidence: In 1959 the Archives of Internal Medicine published an article entitled "Hippocrates and the plane tree on the Island of Kos", by AM Katz. ${ }^{6}$ This paper, inspired by the author's visit to Kos, discusses the perennial plane tree on the main square of the island; according to legend, Hippocrates used to treat his patients and tutor his students in the shade of this plane tree. The author also visited the temple of Asclepios in Kos, and discusses it as a symbol of the pre-scientific era of medicine. Until the rational and scientific medicine of the Hippocratics prevailed over the "healing" practices of priests and soothsayers, these two outlooks on health and disease coexisted, both temporally and spatially. Katz decorates his article with two photographs: one of the plane tree, and one of the temple, with Asia Minor in the background. No less than forty-two years later, Clinical Chemistry and Laboratory Medicine featured an article by MH Dominiczak, a dis- 
tinguished physician and advocate of the medical humanities, entitled "The temple and the plane tree: rationality and cult at the beginnings of western medicine". ${ }^{7}$ The two papers are remarkably analogous: after a similar pilgrimage to Kos, Dominiczak discusses the transition from pre-scientific medicine to the Hippocratic paradigm. Amazingly, he also complements his manuscript with a photograph of the plane tree of Hippocrates, and one of the temple of Asclepios. Is this remarkable fortuity, or merely an example of plagiarism? We suggest that it need not be either! Rather, we believe that this is simply a case in point highlighting the fact that Hippocrates and his legacy have attained a special status: they have become an object of collective memory.

In formal terms, a collective memory comprises a specific community's "shared representation of its past”. In other words, particular groups (ethnic, religious, professional, etc) of individuals tend to develop a communal memory of events and people from their past. For example, as Greeks we have strong collective memories of Alexander the Great and the Revolution of 1821, to mention but two. We all "remember" these events and personalities in more or less the same way, which has been shaped by our schooling and by our community life in general. Social psychology has proposed that memory may reside not in the individual but in the group that the individual belongs to, which is precisely what the term collective memory implies. ${ }^{8}$ Importantly, not all historical events and persons are "strong" enough to create and sustain a collective memory; only those that had a major and lasting impact that altered the course of history. Furthermore, collective memories are retained and reinforced if - and only if - they are considered important and useful for the community's present life. "Just as the key to the future is the past, the key to the past is the present". ${ }^{8}$ The way we think about our past is largely determined by our current needs and desires. Thus, collective memories can be the means to a goal, and quite often they are heavily exploited to serve political agendas.

The mechanism of collective memories is also active in scientific life. Most recently, the bioscientists' collective memory of the discovery of the double helix was extensively utilized to promote the public acceptance and scientific popularity of the Human Genome Project. ${ }^{9}$ A recent volume of Osiris featured a collection of essays by elite historians of science discussing how and why specific scientific discoveries and their protagonists evolved into collective memories. ${ }^{10}$ Knowing that collective memories can be used to promote agendas, it should not come as a surprise that eminent scientists have actively tried - and quite often succeeded - to propagate a version of their discipline's history that would reserve a prominent role for themselves in its present and future. ${ }^{11}$ But there may also be a less selfish and indeed useful reason why collective memories are operative in science. As the philosopher of science TS Kuhn wrote in 1962, "the sciences, like other professional enterprises, do need their heroes and do preserve their names. Fortunately, instead of forgetting these heroes, scientists have been able to forget or revise their works". ${ }^{12}$ According to Kuhn, this mechanism of viewing a scientific discipline's past through the prism of present needs serves to make the historical course of the discipline appear linear, by concealing the occurrence of "scientific revolutions". If unmasked, such major revisions of scientific principles and frameworks - changes of "paradigm" - could undermine the discipline's future by questioning its revered collective memories of the past.

With this understanding of collective memories at hand, we might now be better able to explain why Hippocrates is the best remembered physician in medical history. In a nutshell, Hippocrates made two ground-breaking contributions: he promoted medicine to an art that adhered to scientific methodology, and established it as a profession practiced within a humanitarian moral framework..$^{13}$ In this manner, he streamlined the separation of medical practice from religion and philosophy, thus decisively shaping the future of medicine - twenty five hundred years later the plane tree still bears leaves, whereas the temple is in ruins. The humoral theory remained the credo of medical practice well into the nineteenth century; it was outdated only by the germ theory of disease, which originated from the works of Pasteur, Lister, and Koch, in what could be dubbed a "medical revolution". ${ }^{14}$ Amazingly, the humoral theory is returning to the spotlight in the 
new millennium, and is reinterpreted to accommodate the way we contemplate health and disease in the post-genomic era. ${ }^{15}$ Once again, the present holds the key to the past! Importantly, even though the humoral theory was rendered obsolete by the infectious disease model, Hippocrates's moral guidelines were never surpassed. The Oath is the best known and most discussed work of Hippocrates, and is commonly held as the golden standard for any physician's conduct. ${ }^{16}$ The humanitarian Hippocratic principles are commonly invoked when medicine is believed to be going through a moral crisis, and the Oath is emphasized as a set of moral guidelines that the profession should revert to. The fact that only a very small fraction of physicians and laymen know exactly what the Oath stipulates, exemplifies a more general principle: a group's collective memory does not premise that each individual has a thorough knowledge of the facts.

If we consider Hippocrates as an object of collective memory, then we can probably explain why he was commemorated in an almost identical manner in $2001^{7}$ as he was in $1959 .{ }^{6}$ Every so often, distinguished scholars with a genuine concern about medicine's scientific and moral orientation put forth the Hippocratic legacy as a beacon for the future; as the titles of relevant articles straightforwardly put it, it is "what modern physicians can learn from Hippocrates" $"$ that renders him "still a contemporary". ${ }^{18}$ But we should also bear in mind that, like any other collective memory, Hippocrates and his tradition (especially his apothegms) have been ruthlessly mined to serve various agendas. Hippocrates has been invoked as the founding father of an assemblage of diverse and contrasting medical (as well as para-medical) theories and practices: from the science of medicine to the art of healing, from biomedicine to homeopathy, and from antiabortion legislation to the conduct of doctors in Nazi Germany. ${ }^{19}$ Unfortunately, it is not always easy to discriminate between justified and undue invocations of Hippocrates, for two related reasons: First, the Corpus Hippocraticum is clearly a collection of works by multiple authors. Thus, relatively little is known about the viewpoints and practices of the true historical Hippocrates. Second, even if such information was available, it would still need to be inter- preted within the context of Hippocrates's era. The philosophical concept of historical relativism would suggest that the Hippocratic legacy could mean different things in different times, but the meaning that Hippocrates intended for it would be limited to Hippocrates's timeframe..$^{20}$ To interpret the Corpus in today's light is to automatically enact the collective memory mechanism.

In conclusion, the Hippocratic tradition has had such an impact on medicine that it evolved into a collective memory for physicians, historians, philosophers, and laymen alike. A basic knowledge of the writings of the Hippocratic Collection can significantly augment one's comprehension of the historical, philosophical, and moral foundations of medicine. To this end, the study of secondary bibliography (the present article not excluded!) has a dangerous shortcoming: it may subject the reader to the caveats of the collective memory phenomenon. Therefore, it would be useful if physicians and medical students acquainted themselves with at least some central treatises of the Corpus, such as the Art, Nature of Man, and, of course, the Oath. In that manner, our collective memory of the Hippocratic legacy would be complemented and refined by a better individual understanding of its importance for the present and future of medicine.

\section{REFERENCES}

1. Poulakou-Rebelakou E, Marketos SG, 2002 Endocrine terminology in Coprus Hippocraticum. Hormones 1: 57-58.

2. Kontopoulou TD, Marketos SG, 2002 Homeostasis. The ancient Greek origin of a modern scientific principle. Hormones 1: 124-125.

3. Kontopoulou TD, Marketos SG, 2003 Tracing the origin of the term "gene". Hormones 2: 135-136.

4. Daikos GK, 2003 The Hippocratic spirit. Hormones 2: 186-188.

5. Cantor D (ed) 2002 Reinventing Hippocrates, Ashgate Publishing Ltd, Hampshire.

6. Katz AM, 1959 Hippocrates and the plane tree on the Island of Cos. Arch Intern Med 104: 653-657.

7. Dominiczak MH, 2001 The temple and the plane tree: rationality and cult at the beginnings of western medicine. Clin Chem Lab Med 39: 997-1000.

8. Pennebaker JW, Banasik BL, 1997 On the creation and maintenance of collective memories: history as social psychology. In: Pennebaker JW, Paez D, Rimé (eds) 
Collective memory of political events. Social psychological perspectives, Lawrence Erlbaum Associates, Mahwah.

9. Strasser BJ, 2003 Who cares about the double helix? Nature 422: 803-804.

10. Commemorative practices in science 1999 Historical perspectives on the politics of collective memory. AbirAm PG \& Elliot CA (eds) Osiris; p, 14.

11. Abir-Am PG, 1999 The First American and French commemorations in molecular biology: from collective memory to comparative history. Osiris 14: 324-370.

12. Kuhn TS, 1996 The structure of scientific revolutions, $3^{\text {rd }}$ edition. Chicago University Press, Chicago.

13. Bulger RJ, Barbato AL, 2000 On the Hippocratic sources of Western medical practice. Hastings Cent Rep 30: 4-7.

14. Thagard P, 1996 The Concept of Disease: Structure and Change. Communication and Cognition 29: 445478.

15. Sykiotis GP, Kalliolias GD, Papavassiliou AG, 2005 Hippocrates: A pioneer of genomic medicine? Hormones 4: 55-58.

16. Hippocrates 1923 The Oath. In: Jones WHS (trans) Loeb Classical Library, Hippocrates, Volume I. Harvard University Press, Cambridge, MA.

17. Reiser SJ, 2003 What modern physicians can learn from Hippocrates. Cancer 98: 1555-1558.

18. Merikas G, 1992 Hippocrates: still a contemporary. Humane Med 8: 212-218.

19. van der Eijk PJ, 2002 Hippocrates: The protean father of medicine. Lancet 359: 2285.

20. Clouser KD, 1994 Historical relativism in bioethics: can we judge the standards and conduct of those who preceded us? APA News Philos Med 94: 124-126. 